\title{
Erratum to: Can Wear Explain the Histological Variation Around Metal-on-metal Total Hips?
}

\author{
Edward Ebramzadeh PhD, Patricia Campbell PhD, Timothy L. Tan MD, \\ Scott D. Nelson MD, Sophia N. Sangiorgio PhD
}

Published online: 31 October 2016

(C) The Association of Bone and Joint Surgeons (R 2016

\section{Erratum to: Clin Orthop Relat Res (2015) 473:487-494 DOI 10.1007/s11999-014-3874-5}

One of the authors of the study, "Can Wear Explain the Histological Variation Around Metal-on-metal Total Hips?" listed the incorrect dollar amount range in his conflict of interest statement.

The correct conflict of interest statement for Scott D. Nelson MD should be: "One of the authors (SDN) consults for Depuy Synthes (Warsaw, IN, USA) and Stryker Orthopaedics (Mahwah, NJ, USA). One of the authors certifies that he, (SDN) or a member of his immediate family, has or may receive payments or benefits, during the study period, an amount of USD 100,001-USD 1,000,000 from DePuy Synthes, and an amount of USD 100,001USD 1,000,000 from Stryker Orthopedics."

The authors apologize for the error.

The online version of the original article can be found under doi:10.1007/s11999-014-3874-5.

E. Ebramzadeh ( $)$, P. Campbell, T. L. Tan, S. N. Sangiorgio The J. Vernon Luck, Sr, MD Orthopaedic Research Center, UCLA, Los Angeles, CA, USA

e-mail: edward.ebramzadeh@ucla.edu; ebramzad@usc.edu

P. Campbell

e-mail: pcampbell@mednet.ucla.edu

S. N. Sangiorgio

e-mail: ssangiorgio@ucla.edu

E. Ebramzadeh, P. Campbell, T. L. Tan, S. N. Sangiorgio Department of Orthopaedic Surgery, Orthopaedic Institute for Children, 403 West Adams Boulevard, Los Angeles, CA 90007, USA

\section{S. D. Nelson}

Department of Pathology, Santa Monica UCLA Medical Center, 1250 16th Street, Santa Monica, CA 90404, USA

e-mail: sdnelson@mednet.ucla.edu 